\title{
Research Paper \\ Managing big data in cloud computing and its impact on E-learning in university
}

Journal of

\section{TANMIYAT AL- RAFIDAIN}

\section{(TANRA)}

A scientific, quarterly, international, open access, and peer-reviewed journal

Vol. 40, No. 130

June 2021

(C) University of Mosul | College of Administration and Economics, Mosul, Iraq.

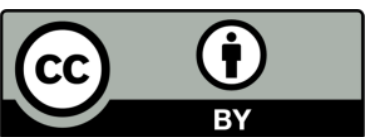

TANRA retain the copyright of published articles, which is released under a "Creative Commons Attribution License for CC-BY-4.0" enabling the unrestricted use, distribution, and reproduction of an article in any medium, provided that the original work is properly cited.

Citation: Luqman Qader Abdulrahman. (2021). "Managing big data in cloud computing and its impact on, E-learning in university". TANMIYAT ALRAFIDAIN, 39 (126), 277 -291, https://doi.org/10.33899/tanra.20 20.128428 .1057

P-ISSN: 1609-591X e-ISSN: 2664-276X tanmiyat.mosuljournals.com

\section{Luqman Qader Abdulrahman ${ }^{1}$}

${ }^{1}$ College of Health Sciences, Halwer Medical University

Corresponding author: Luqman Qader Abdulrahman. College of Health Sciences, Halwer Medical University.

DOI: https://doi.org/10.33899/tanra.2020.128428.1057

Article History: Received: 12/8/2020; Revised: 31/8/2020; Accepted: 14/10/2021; Published: 1/6/2021.

\section{Abstract}

With the spread of the COVID 19 pandemic, universities have become heavily dependent on platforms, applications, and ready-made programs that help professors, this issue would make the data continuously available, and everyone could quickly get it. Also, this facilitates the analysis and use of this data to improve educational effectiveness and support basic research on learning. Besides, it is characterized by the need for rapid treatment so that it can display the common points, trends, and patterns in the behavior of the target group. In the university, data analysis can have a major impact on all employees from teachers to students and even coaches in educational leadership and management. Many educational institutions receive a large amount of information daily in the form of details about attendance and participation, test results, students' evaluations of teachers, and also details about their social and economic situation. Hence, such "Big Data" collection and the analysis which follows allow educational institutions to begin providing more personalized education. Reliance on "Cloud" has become very necessary to accelerate the pace of work and the services of the university. Cloud computing is characterized by electronically managing data, ensuring data confidentiality, and archiving it in a safe, accurate and usable manner. There is a large group of universities that rely heavily on cloud computing and have developed in the electronic educational process in terms of giving excellent service to students and professors, so in this research we suggest universities to start using cloud computing because of its many advantages.

\section{Keywords}

Big Data, Cloud Computing, Data Management, application, platform. 


\section{ورقة بحثية التعليم الألكتروني في الضات الضخمة في الحوسبة السحابية واثرها على}

لقدان قادر عبدالرحمن'

' كلية العلوم الصحية/ جامعة أربيل الطبية

المؤلف المراسل: لقمان قادر عبدالرحمن كلية العلوم الصحية/ جامعة أربيل الطبية

DOI: https://doi.org/10.33899/tanra.2020.128428.1057

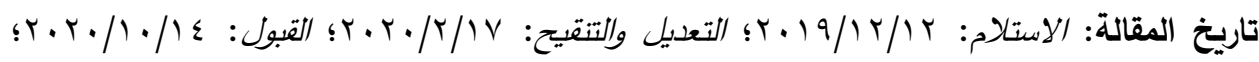
النشر:

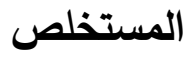

مع انتشار جائحة 19 COVID ، أصبحت الجامعات تعتدد بشكل كبير على المنصات والتطبيقات

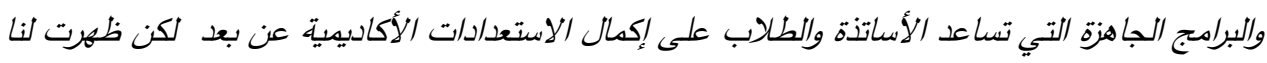

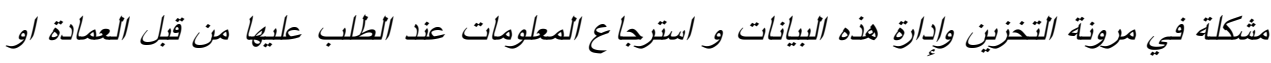

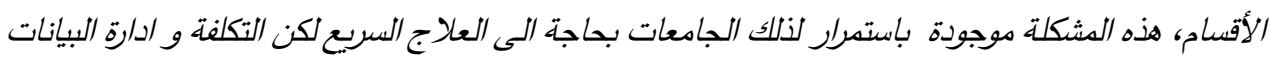

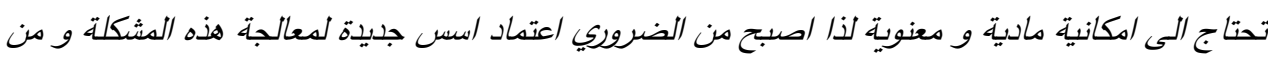

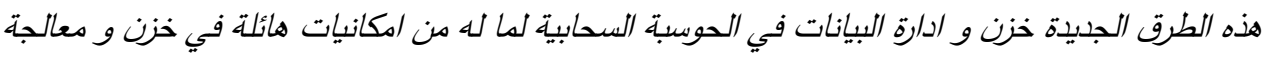

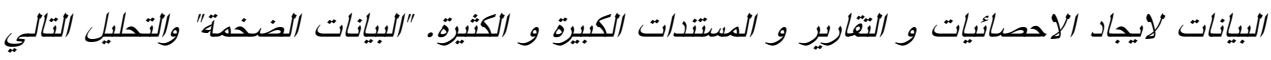

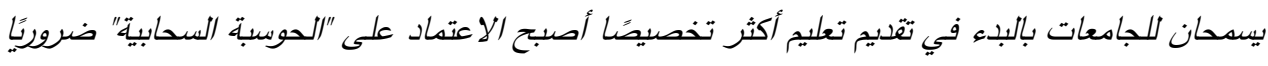

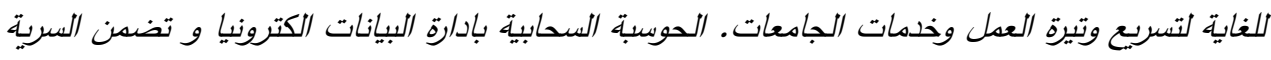

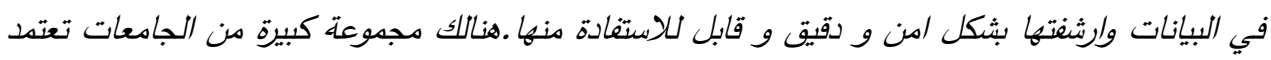

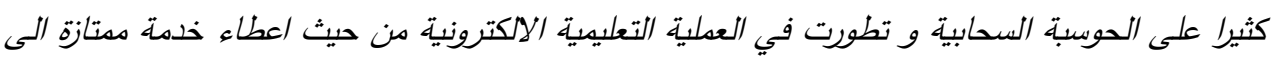
الطلاب و الاساتذة لذا نحن في هذه البحث نقترح على جامعات البدء في استعدال الحوسبة السحابية لها له له

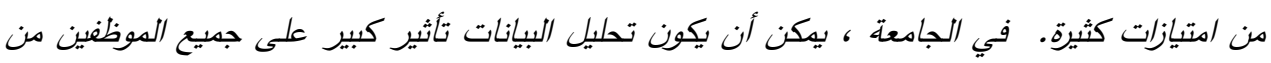

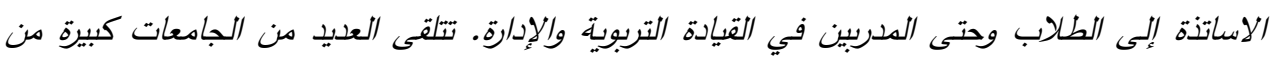

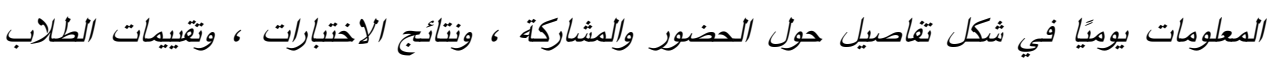
للمعلمين، وكذلك تغاصيل حول وضعهم الاجتماعي والاقتصادي.

\section{الكلمات الرئيسة}

البيانات الضخمة ، الحوسبة السحابية ، إدارة البيانات ، التطبيق ، المنصة

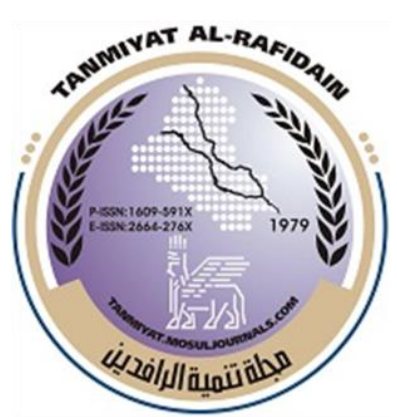

هملة

\section{تنمئة الرافدبن}

(TANRA) دولية، مفتوحة الوصول، محكمة.

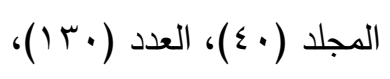
حزيران (r.r.

(ج) جامعة الموصل | كلية الإدارة والاقتصاد، الموصل، العراق.

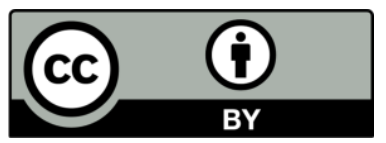

تحتف (TANRA) بحقوق الطبع والنشر للمقالات

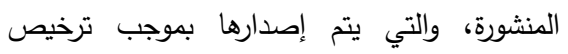
」 (Creative Commons Attribution) (CC-BY-4.0)

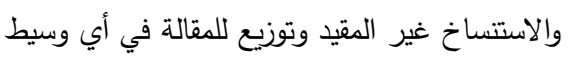
نقل، بشرط اقتباس العمل الأصلي بشكل صحيح.

الاوتباس: لقمان قادر عبدالرحمن ( إب · (Y).

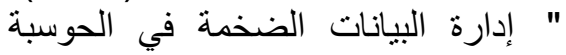

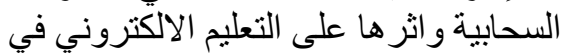

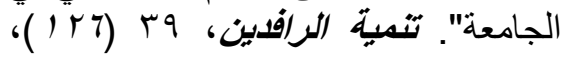
6 Tq1-TVV

https://doi.org/10.33899/tanra.20 20.128428 .1057

P-ISSN: 1609-591X

e-ISSN: 2664-276X

tanmiyat.mosuljournals.com 


\section{Introduction:}

Internet software that records 250 thousand hours of use by students in a short time in addition to having nearly 30 million visits by students during different periods of the year and the resulting data of the processes and interactions that ensue from circulating texts and media creates a great challenge for professionals to collect, analyze, read well, and extract results from it. Furthermore, such data comes from various and varied sources and forms with varying degrees of reliability in one way or another. Consequently, this analyzes such enormous data in need of controlling how the main methods are used to extract educational data and to analyze the educational value of this data. It also needs to account for the methods being developed by researchers in different respects. One of these methodological areas includes extracting and examining educational data by conducting a learning analysis. Another revolves around large-scale learning, modeling, and artificial intelligence societies, in addition to learning when and how to apply these methods. Aldakheel, (2011). For example, a college professor wants to know how many students have used service websites to write reports on their behalf, and the surveyor interview will not provide reliable data. No student will admit to purchasing readymade content from these sites. In this case, the professor can resort to data analytics. One can, for example, use the "Google Keyword Planner" tool to see results for relevant search terms and how many students from that city are looking for a phrase like: "Write an article on my behalf" on Google. Big data and its technologies can help schools and universities analyze results from different circles and forecast trends to enhance teaching methods. Instead of trying to think about the reasons why students are not making progress, they will research the data and identify the exact factors. After that, they will make changes that remove obstacles and encourage learners to move forward. This may require changing the rules of the game to improve student outcomes, by exploiting the huge data created by technology and employing the enormous potential offered by learning analyzes to produce results that satisfy the student on the one hand and the university on the other hand. Learning analyzes of students have proven their ability to determine the most appropriate time of the day to learn and the most effective ways for them. It can also allow lecturers to stimulate more student participation. Analysis of these types of big data can be used in education to provide a variety of opportunities and options to improve students' learning and personalize students' paths to content mastery. Bashir al., (2018).

Some universities relied on ready platforms, but some universities that have specialized cadres in the field of programming, design, and databases; designed their database and were linked by the "Cloud", which was safer, more accurate, and less problematic. However, the only thing it requires is before management from the university's cadres.

\subsection{Statement of the Problem:}

Using ready applications or those which have been designed by the universities during the educational process from the beginning of the school year to announce students' results, store, arrange and analyze them; requires a large site

TANMIYAT AL-RAFIDAIN (P-ISSN: 1609-591X; E-ISSN: 2664-276X) تنمية الرافدين 
with the use of the However, it will inevitably face major problems such as the periods of lectures and the amount downloaded by students. Also, because these universities face major problems at the end of the school year when it comes to distributing results by having a password given for every student and the fact that the download is large, the university servers will not be able to bear the burden of such operations in the record and due times. Therefore, the educational system must be modified to accommodate these needs. Academic supervisors should also raise awareness of this for both students and teachers to increase students' chances of success and staying on the educational track until graduation.

\subsection{Importance and Objectives of the Research:}

This research aims at explaining how the data is managed by the cloud that benefit students, professors, and university administration and link them together and then introduce them into the cloud computing system. Such a system is more transparent and credible in education and the opportunities for education and participation are equal among students. In this system, lazy students would run into a problem in loading attendance, daily exams, and weekly and monthly homework.

\subsection{Importance of the Research:}

The research aims at that appear by explaining the dimensions of linking the teaching process from $\mathrm{A}$ to $\mathrm{Z}$ with cloud computing and generating very large data through the information of each student, lecture, educational video, and discussion that take place during the lecture between lecture and students and between students together. The study also aims at explaining the projects to the students by introducing them to data management in a scientific manner and in a way that does not violate the approved educational constitutions. In other words, the study tries to clarify to administrators in the universities the way to adopt a procedure to link this information and get benefit out of it for the coming years by adopting new plans and addressing the problems which occurred during the previous years.

Many universities during the epidemic of COVID 19 had to complete the school year 2020-2019 by applying a model such as Edmundo or Classroom. Such universities faced great problems such as having a slow internet connection. They also had to use a large server. The research of this study suggests using Google Classroom in conjunction with Google Drive to store big data generated from exams and information about students and the university as a whole.

Through this research, the paper attempts to know how to handle big data when dealing with it in cloud computing, and to choose more effective methods that should be adopted by the universities that are in the list of acknowledged universities. Furthermore, the research tries to account for the way developed universities have benefited from linking the educational process with cloud computing and managing it in a way that satisfies students and professors about a new lifestyle to reach perfection and excellence in education.

\subsection{Literature Review:}

(Change al., 2012) found that with the rapid development of an emerging application such as social network analysis, and vital information network analysis,

TANMIYAT AL-RAFIDAIN (P-ISSN: 1609-591X; E-ISSN: 2664-276X) تنمية الرافدين 
a large set of data must be processed and still witness a lot In speed. In their study, the researchers found that the effective management and efficient analysis of big data is an interesting but serious challenge. Recently, big data has attracted much interest from universities, educational institutions, and government ministries. Chang et al (2012) introduced several techniques for manipulating big data from system and application.

(Klim, 2017) defines the database as a set of data arranged and distributed in a way that allows the user to access it easily and appropriately. However, in the age of big data, old ways of data management cannot manage this amount of data. Therefore, to develop an effective way to manage this big data, (Sahar, 2017) studies the use of the Map-Reduce technology in the field of big data distributed on the computerized cloud. This technique was evaluated by using the Hadoop server and was applied to data taken from EEG images as a case study.

Researchers (Nabil, al. 2017) have studied big data and cloud computing from several important aspects, and the researchers concluded that the relationship between them is integral. It turns out that big data and cloud computing constitute an integrated model in the world of distributed network technology. Researchers in developing big data and its requirements are a factor that motivates service suppliers in the cloud to continually develop because the relationship between them depends on the product, storage, and processing as a common factor, information data analysis.

\section{Cloud Computing and Big Data:}

\subsection{Defining Big Data:}

Big data represents an important stage in the development of information and communication systems, and it expresses in its simplified concept a huge amount of complex data that exceeds the capacity of traditional software and computer mechanisms to store, process and distribute it, which led to the development of advanced alternative solutions that enable control of its flow and control. on her. Big data is a group of data of various classifications that have unique characteristics (such as size, speed, diversity, variance, data validity) that cannot be efficiently processed using current and traditional technology to benefit from it. Dong, (2009).

The data revolution is a term for the open data movement, the new global information, and communication technologies to collect data, and the massive flow of big data availability, especially with the emergence of artificial intelligence and the Internet of things. Big data has the advantage of helping universities improve processes and make decisions faster, but in some cases negative decision-making is if the data analysis is uncluttered. through the enormous information it provides, as data is collected from many sources such as social media, programs, mobile phone applications, databases, and even servers, etc., through questionnaires and after collecting This data is processed, filtered, and then analyzed according to what universities and educational institutions want. Ahuja al. (2013).

\subsection{Types of Big Data:}

Big data have three types: see Fig. -1-.

TANMIYAT AL-RAFIDAIN (P-ISSN: 1609-591X; E-ISSN: 2664-276X) تنمية الرافدين 

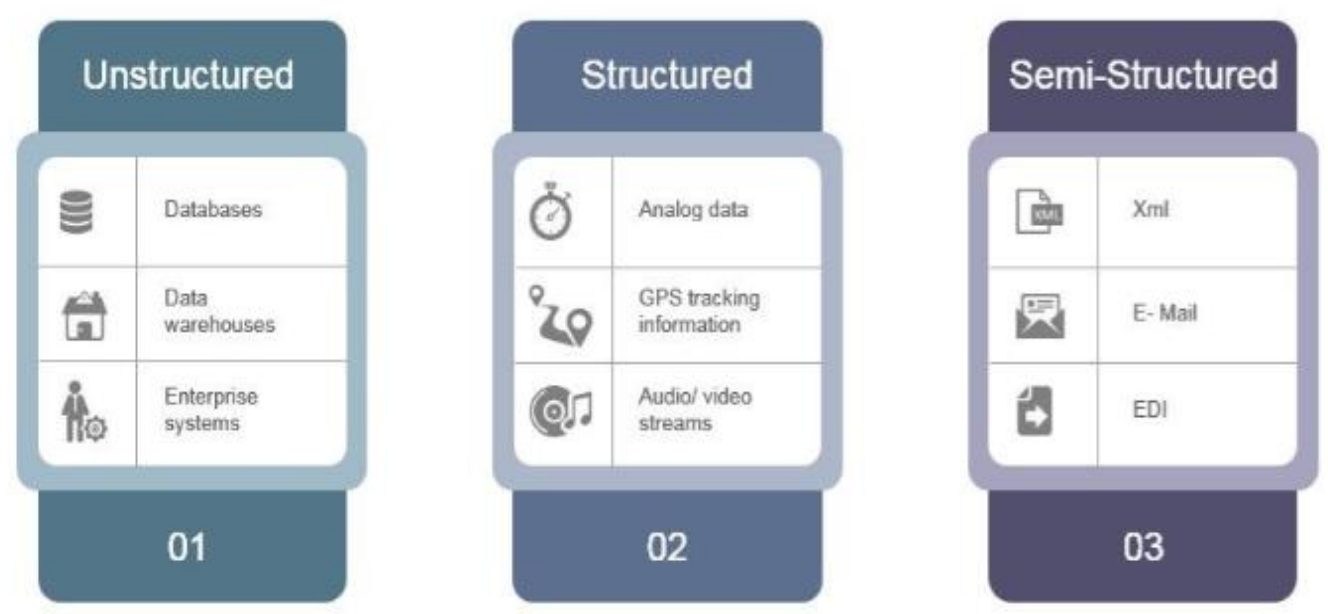

\subsubsection{Structured data:}

Fig. -1- The Big Data Types. Yusuf Perwej (2017).

Data that can be stored, accessed, and manipulated in the form of a fixed format is called structured data so that formatting exists and values are predefined. When there is a lot of data, big problems occur in processing the data. Data is stored systematically in databases. All data from sensors, weblogs, and ready-made applications are categorized within the data created to be able to address problems and absorb big data. For example, the examination system, the student admission system in universities, the library system, etc., and the enormous amount of data that is usually transferred between the professor and the student via trading platforms. So it is the structured data that the human creates all the data that the human enters into the device. Ebner al., (2007).

\subsubsection{Unstructured data}

Classify any data of unknown shape or structure as unstructured data. In addition to high volume, unstructured data pose multiple challenges in terms of processing it to extract value from it. The typical example of unstructured data is a heterogeneous data source that contains a combination of text files, images, etc. And video clips for example student lectures, etc. Organizations today have a wealth of data available with them but unfortunately, they do not know how to extract value from it since this data is in raw or unstructured form. Structured data is found in traditional row-column databases, the unstructured data is: They don't have a clear format in storage. The rest of the data is generated, about $80 \%$ of the total unorganized big data account. Most of the data a person encounters belong to this category - until recently, there wasn't much to do other than store or analyze it manually. Unstructured data are classified based on their source, either into machine-generated data or man-made data. The automatically generated data represents all the satellite images and scientific data from various experiments. Franks, (2012).

TANMIYAT AL-RAFIDAIN (P-ISSN: 1609-591X; E-ISSN: 2664-276X) تنمية الرافدين 
The classification of unstructured data is -

\section{A. Captured data:}

It is data based on user behavior, for example, smartphones that help the user in the current time and provide real-time outputs.

\section{B. Generated data User:}

Unstructured data The user places the data on the Internet by himself step by step for example, tweets, likes, shares, comments, on Twitter,

\subsubsection{Semi-structured:}

Instagram, TikTok, Facebook, etc.

Structured data has a good level of organization, which makes it predictable, easy to organize, and quickly searched using advanced algorithms. So that the information is arranged scientifically, the data is entered into specific fields that contain text or numerical data, so the organized data has fixed rules for accessing it.

For example, MySQL documents are semi-structured, containing keywords that can be used to easily manipulate the document. Semi-structured information can contain both forms of information. We can see semi-structured data as a system in the figure but it is not defined for example. See Table 1, which shows the difference between big data types. Ahuja, al., (2013).

\section{Table -1}

It explains the difference between the big data types. A. Gandomi, (2017)

\begin{tabular}{|c|c|c|c|}
\hline Factors & Structure & $\begin{array}{r}\text { Semi- } \\
\text { structured }\end{array}$ & Unstructured \\
\hline Adaptability & $\begin{array}{l}\text { It is less flexible } \\
\text { and dependent }\end{array}$ & $\begin{array}{l}\text { flexible than } \\
\text { structured } \\
\text { information but } \\
\text { less flexible than } \\
\text { unstructured } \\
\text { information }\end{array}$ & $\begin{array}{l}\text { It has no schema and is } \\
\text { flexible }\end{array}$ \\
\hline $\begin{array}{l}\text { Proceedings } \\
\text { Management }\end{array}$ & $\begin{array}{l}\text { various } \\
\text { concurrency } \\
\text { technique }\end{array}$ & $\begin{array}{l}\text { adapted from } \\
\text { DBMS not } \\
\text { matured } \\
\end{array}$ & $\begin{array}{l}\text { No bargain no } \\
\text { synchronization }\end{array}$ \\
\hline $\begin{array}{l}\text { Effectiveness } \\
\text { Query }\end{array}$ & $\begin{array}{l}\text { construct query } \\
\text { allows } \\
\text { combination } \\
\text { retraction }\end{array}$ & $\begin{array}{l}\text { Queries are } \\
\text { plausible in the } \\
\text { case of } \\
\text { anonymous nodes }\end{array}$ & An only textual query \\
\hline Technology & $\begin{array}{l}\text { based on the } \\
\text { relational database } \\
\text { table }\end{array}$ & $\begin{array}{l}\text { It is Depends on } \\
\text { RDF and XML }\end{array}$ & $\begin{array}{l}\text { It depends on character } \\
\text { and library }\end{array}$ \\
\hline
\end{tabular}

\subsection{Cloud Computing?}

Cloud computing is a new, cheaper, more secure solution than the existing IT solutions which would allow them to share information between students and university databases. Nowadays, universities are deploying cloud computing facilities like Google, Microsoft, and other services to implement e-mail, Calendar, and document management, and other office software. 
There are many definitions of cloud computing but the most accepted one is defined by the National Institute of Standards and Technology (INIST) which describes the technology by saying that. Cloud computing is the ubiquitous, ergonomic, and on-demand network access model to a common set of configurable computing resources (such as networks, servers, storage, applications, and services) that can be provided and released quickly with minimal effort or service provider interaction. Boyd, al., (2011).

\subsubsection{Cloud Architecture:}

According to INIST it has five characteristics:

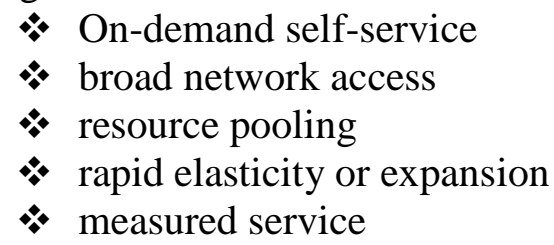

\subsubsection{Service Models}

\section{- $\quad$ Software as a service (SaaS):}

The user can use the online user interface without any installation of any application-specific software). SaaS delivers the applications which are from the server in the cloud and the connection point between the end-user and services like recording application, report application in different fields like health, education, and economics.

\section{- $\quad$ Platform as a service (PaaS):}

This PaaS provides the users, like the computer programmer or application developers, the operating system, and databases for developments. It helps the software developer deploy a program without worrying about hardware and software requirements. Therefore, this service is available on cloud computing to operate the collected information between IaaS and SaaS. PaaS is available on Microsoft's Azure Services Platform and Google Apps Engine.

- Infrastructure as a service (IaaS):

Companies pay a charge to use cloud computing, networks, and the required capacity. Key Challenges in Cloud Computing: Enabling the Future Internet of Services. This payment is for the way that fuel, electricity, and water is consumed as the user uses the cloud virtually. Agrawal, al., (2011).

\subsubsection{Deployment Models}

There are four different types of cloud:

1. Private cloud: This type of cloud is used exclusively for sharing data in one organization without being available to the public.

2. Public cloud: This infrastructure is available for all public users. Public clouds can be used for marketing, educational purposes, or government organization.

3. Community cloud: This is used by exclusive users from several different organizations that have common goals.

4. Hybrid cloud: This deployment type consists of a combination of two or more cloud infrastructures. In this way, part of the infrastructure runs in a

TANMIYAT AL-RAFIDAIN (P-ISSN: 1609-591X; E-ISSN: 2664-276X) تنمية الرافدين 
private cloud while the other part runs in public clouds. Therefore, it offers more flexibility than those of public and private clouds. Géczy, al., (2012).

\section{Methodology:}

\subsection{How to store big data in cloud environments:}

Nowadays there are a lot of individual web applications that can generate large quantities of data every second, for example, every day 500 terabytes of data are stored in Facebook databases and more than 360 terabytes of information are uploaded to Google. The growth of data in cloud environments is increasing exponentially and rapidly with the increasing number of users connected to the Internet around the world.

How do you store this massive amounts of data in cloud environments? We need storage technology that meets the needs of rapidly growing data on the cloud. We need low-cost storage technology, high reliability, high capabilities, and new formats that work with everyone.

Distributed File Storage System stores a large number of files as they are divided into several clusters. Each block consists of a set of nodes. The group HDFS cluster includes three types:

1. Name Node acts as the master node that controls the collection of storage. It splits data into groups, each group being copied three times and storing in a block.

2. Data Node works on server nodes and provides error tolerance. If the server node fails, the upcoming versions of the Name Node ensure that the system will not crash or fail in this way.

3. The client machine can be a Data Node or Name Node, on which the Hadoop system is installed. It loads the data into the block, provides jobs to Map Reduce. Lordan, al., (2014).

MySQL disseminated databases are used to meet the oppressions of analyzing and processing large amounts of unstructured or unstructured data. MySQL databases have solved the problems of concurrency, scalability, and fault tolerance that have encountered traditional relational databases. Like the traditional SQL (Structured Query Language) database, MySQL also uses queries, but it does not restrict its use alone. It may use languages other than SQL. Ercan, (2010).

\subsection{Analysis of Big data in cloud computing:}

The analysis of big data in cloud environments is divided into two main types: batch offline and real-time, in the first type of batch offline. Large batches of data are processed automatically without any exchange or monitoring by the user. After collecting data, all data is processed simultaneously. Examples include Hadoop and Map Reduce. Map Reduce is a programming model developed by Google based on GFS for processing a large number of data sets. It uses a wide range to automatically perform parallel tasks and operations using a program like Hadoop. It can be applied to searching for websites and other web applications. The map-Reduce algorithm includes two functions: the Map function to convert items in one type of list to another type and place them again in the same type of list. Then filtering and sorting operations are performed. Reduce function to collect

TANMIYAT AL-RAFIDAIN (P-ISSN: 1609-591X; E-ISSN: 2664-276X) تنمية الرافدين 
the items in the output lists from the Map and perform some calculations on each of them to reduce them in one value. Lopez, (2012).

Hadoop Map Reduce is an implementation of the Map-Reduce algorithm. It was developed by the Apache Project and includes several stages; each stage has a set of processes to produce the desired result for the user. The process begins at the user's request to run Map-Reduce and continues until results have been written to HDFS. Several Hadoop and Map Reduce based systems developed. Apache Hive is a Hadoop-based data warehouse program. In the real-time analysis, when data is entered by the user, it is processed straightway, and the user needs to wait for a squat period not exceeding a millisecond.

\subsection{Relationship between cloud computing and big data?}

Enormous amount of data is generated, cloud computing has an important role in storing and managing that data. It's not just about the growth of big data but the expansion of information analytics platforms like Hadoop. It creates new opportunities in cloud computing then; service providers such as AWS, Google, and Microsoft deliver their big data systems in an outlay-effective and scalable manner for businesses of all sizes (see Figure 2).

A faster and scalable way to integrate, analyze, transform, and visualize different types of structured, semi-structured, and unstructured data in real-time. Cloud computing relationships for big data can be evaluated according to the following perspectives and benefits:

- The cloud computing environment contains many user stations. At collection stations. The user collects data using big data tools on the part of the service provider; it maintains stores and processes big data. Cloud computing provides an infrastructure for big data. Infrastructure, resources, and services should be available on-demand to ensure service without interruption.

- The cloud environment is scalable, so it can provide suitable solutions for data management regardless of the size of the data. Enables the necessary cloud computing service provider also to provide security policies according to the user's requirements if it is a student, university teachers, or administrator.

- Access control is a concern during a relationship with confidential company information. Cloud computing can meet security requirements using a programming interface by summarizing the internal details of the information. This ensures complete confidentiality of user data and provides access only to users whom the administration has given permission.

- The big data site for data processing is located across popular locations, and maintaining such huge servers in different locations is a costly measure for a university or educational institution because cloud computing can be stored.

- Cloud computing helps the elevation-speed information flow across the network cause a lot of data to be processed faster. Mohd, (2020)

TANMIYAT AL-RAFIDAIN (P-ISSN: 1609-591X; E-ISSN: 2664-276X) تنمية الرافدين 


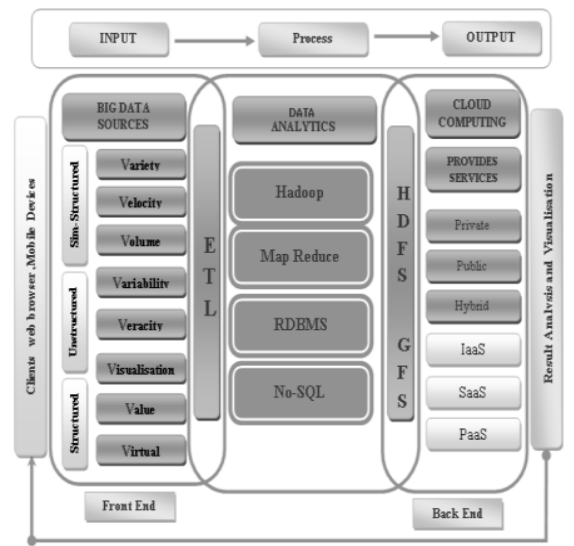

Fig 2. Relationship between Data, and Cloud Computing [Mohd M., 2020].

\section{Recommendations:}

This study has the following recommendation in mind:

- It is recommended that decision-makers at universities or the related authorities have a much better understanding of Cloud Computing, how to employ it, and all the current ideas which can be made use of when using it in addition to achieving a balance between advantages and expenses.

- A proposed introductory model should be designed and represented in managing the requirements of the University for the Resources of information and communication technology and to provide a program and store data with the goals of the employed computing.

- To adopt could compute in the university level whether publicly or privately and to identify all possible chances and benefits to alternate from current arrangements to cloud services, and encouraging Teaching staff instructors/researchers to gain an advantage from cloud computing.

- To provide a computer-generated data center for students and members of the faculty in the college to save class notes, lectures, and projects and obtain the most recent updates in software and application regardless of time or place.

- To intensify preparation sessions for members in the faculty and students to come into terms with the needed or important qualifications and to improve the technical performance of employing cloud applications when instructors teach or when students learn.

- To adopt straightforward plans scientifically and a future course of action for the cloud computing in the educational process and to carry out developmental research, and make use of research conducted at the university on cloud use and performance. Londhe, al., (2013)

\section{Conclusion:}

Cloud computing technology provides a suitable and compatible framework for big data through ease of use, speed in accessing data, low

TANMIYAT AL-RAFIDAIN (P-ISSN: 1609-591X; E-ISSN: 2664-276X) تنمية الرافدين 
cost in using resources on demand and supply, and also reducing the use of hard equipment used to deal with big data. Together, the cloud and big data emphasize transparency, especially for exam panels, and the speed with which exam results are announced. We can extrapolate a positive image about the openness of our academic institutions to the revolution in technology and information sources, and where many institutions of higher education are witnessing a qualitative shift and an increasing demand from teachers and students to use e-learning systems that have become available efficiently and effectively and are easy to obtain by expert bodies in this field. Today, in light of this technological revolution and big data, there is no longer an excuse to maintain the traditional style of education. What we need today is education that is open to the future, capable of keeping pace. Control over the big data that exists in the presence of cloud computing so that universities an benefit from it, provided that there is an application or program designed for use in the field of university education in particular. There is an integral relationship between cloud computing technologies and big data and how they are handled with big data in cloud computing environments. Cloud computing differs from traditional computing in a lot in size and can provide users with various levels of services that can be configured based on previously taken approvals. By working in the university academic year, the volume of data in cloud computing environments increases greatly and this is an increase in the diversity of data contents and sources. Providing open source technologies for the cloud is a challenge that has led to a very large increase in data, which led to the use of more users, and this is the main feature that makes Hadoop the most used program for processing big information in the cloud environment.

It is possible to say the following:

- Cloud Computing has both advantages and disadvantages; however, we take the perspective that in the context of higher education, it is regarded as an essential element for electroniclearning.

- Distant learning can best be achieved by using social networking sites which can enhance the abilities and skills of students, and consequently could provide a global-communication situation, which allows for increasing admission to data associated with the fields of studies they are studying.

- Privacy, security and confidentiality are the biggest challenge facing teachers, researchers, and trainers when using cloud computing.

- Education will improve when the college/university has the willingness to make use of the benefits of Cloud Computing educationally by giving cutting-edge services like making registration and admission simpler and renewable in addition to protecting data and files.

TANMIYAT AL-RAFIDAIN (P-ISSN: 1609-591X; E-ISSN: 2664-276X) تنمية الرافدين 


\section{REFERENCES:}

1. Gandomi and M. Haider. Beyond the hype. Big data concepts, meth-odds, and analytics. International Journal of Information Management, Vol. 35, No. 2. 2015

2. Agrawal, D., Das, S., and El Abbadi, A. Big data, and cloud computing: current state and future opportunities. in Proceedings of the 14th International Conference on Extending Database Technology. ACM. 2011

3. Ahuja, S. P., and Moore, B. State of Big Data Analysis in the Cloud. Network and Communication Technologies, Vol. 2, No. 1. 2013.

4. Aldakheel, E. A. A Cloud Computing Framework for Computer Science Education. Bowling Green State University. Armbrust, M., Fox, A., Griffith, R., Joseph, A. D., Katz, R., Konwinski, A., and Stoical, I. A view of cloud computing. Communications of the ACM, Vol. 53, No. 4. 2011.

5. Barbulescu, M., Grigoriu, R., Halcu, I., Neculoiu, G., Sandulescu, V. C., Marinescu, M., and Marinescu, V. Integrating of structured, semi-structured and unstructured data in natural and build environmental engineering. In Roedunet International Conference 2013 11th. IEEE. 2013.

6. Bashir Mohammad, Mariam Kiran. Experimental Report on Setting up a Cloud Computing Environment at the University of Bradford. School of Electrical engineering and computer science, Bradford University BD7 4DP. 2018

7. Boyd, D., and Crawford, K. Six provocations for big data. A decade in internet time: Symposium on the dynamics of the internet and society. Vol. 21. Oxford: Oxford Internet Institute. 2011.

8. Change qing Ji, Yu Li, Wenming Qiu, Uchechukwu Awada, Keqiu Li. Big Data Processing in Cloud Computing Environments. International Symposium on Pervasive Systems, Algorithms, and Networks. 2012.

9. Dong, B., Zheng, Q. An E-learning Ecosystem Based on Cloud Computing Infrastructure. The Ninth IEEE International Conference on Advanced Learning Technologies, China. 2009.

10. Ebner, M., Holzinger, A., and Maurer, H. Technology: future interfaces for technology-enhanced learning? Universal Access in Human-Computer Interaction. Applications and Services. 2007.

11. Ercan, T. Effective use of cloud computing in educational institutions. Procedia: Social and Behavioral Sciences, Vol .2, No. 2. 2010.

12. Franks, Bill. Taming the big data tidal wave: Finding opportunities in huge data streams with advanced analytics. Vol. 49. John Wiley and Sons. 2012.

13. Géczy, P., Izumi, N., and Haida, K. Cloud sourcing: Managing cloud adoption. Global Journal of Business Research, Vol. 6, No.2. 2012.

14. Gütl, C., and Chang, V. Ecosystem-based theoretical models for learning in environments of the 21 st century. International Journal of Emerging Technologies in Learning, No. 3. 2008.

15. Hong-Linh Troung, Tran-Vu Pham, and Nam Thoai. Cloud Computing for Education and Research in Developing Countries. IGI Global. Copying or

TANMIYAT AL-RAFIDAIN (P-ISSN: 1609-591X; E-ISSN: 2664-276X) تنمية الرافدين 
distributing in print or electronic forms without written permission of IGI Global is prohibited. 2012.

16. Klim, W. Cloud Computing. Status and Prognosis, in Journal of Object Technology, Vol. 8, No.1. 2017.

17. Londhe, S. R., Mahajan, R. A., and Bhoyar, B. Overview on Methods for Mining High Utility Itemset from Transactional Database. International Journal of Scientific Engineering and Research (IJSER), Vol. 1, No. 4. 2013.

18. Lopez, Xavier. Big data and advanced spatial analytics. In Proceedings of the 3rd International Conference on Computing for Geospatial Research and Applications. ACM. 2012.

19. Lordan F, Tejedor E, Ejarque J, Rafanell R, Alvarez J, Marozzo F, Lezzi D, Sirvent R, Talia D, Badia RM. Services: An interoperable programming framework for the cloud. J Grid Computer, Vol. 12, No.1. 2014.

20. M. K. Kakhani, S. Lakhani, and S. R. Biradar. Research issues in big data analytics. International Journal of Application or Innovation in Engineering and Management, Vol. 2, No.8. 2015.

21. Maniar, K. B., and Khatri, C. B. Data Science: Bigtable, MapReduce, and Google File System. International Journal of Computer Trends and Technology (IJCTT), Vol. 16, No. 03. 2014.

22. Martin A, Brito A, Fetzer C. Real-time social network graph analysis using streaming. In: Proceedings of the 10th ACM International Conference on Distributed and Event-based Systems, ACM, New York, NY, USA, DEBS '16. 2016.

23. Mayer-Schönberger, V., and Cukier, K. Big data: A revolution that will transform how we live, work, and think. Houghton Mifflin Harcourt. 2013.

24. Mohd M. Cloud Computing Techniques for Big Data. Book. Eureka Publication - Pune. 2020.

25. Mukhopadhyay, D., Agrawal, C., Maru, D., Yale, P., and Gadekar, P. Addressing Name Node Scalability Issue in Hadoop Distributed File System Using Cache Approach. In Information Technology (ICIT), International Conference on, IEEE. 2014.

26. Nabeel Z. , Abdullah A., and Sufian M. K. Cloud Computing and Big Data is there a Relation between the Two: A Stud., International Journal of Applied Engineering Research ISSN 0973-4562 Vol. 12, No. 17. 2017.

27. Palmer, R., and Dodson, L. Distance learning in the cloud: Using $3 G$ enabled mobile computing to support rural medical education. Journal of the Research Center for Educational Technology, Vol. 7, No. 1. 2011.

28. Parvin Ahmadi Doval Amiri and Mina Rahbari Gavgani. A Review on Relationship and Challenges of Cloud Computing and Big Data: Methods of Analysis and Data Transfer. Asian Journal of Information Technology, Vol. 15, No.5. 2016.

29. Peng J, Zhang X, Lei Z, Zhang B, Zhang W, Li Q. Comparison of several cloud computing platforms. In: IEEE of the second international symposium on information science and engineering (ISISE). 2009.

TANMIYAT AL-RAFIDAIN (P-ISSN: 1609-591X; E-ISSN: 2664-276X) تنمية الرافدين 
30. Pocatilu, P. Alecu, F., and Vetrici, M. Measuring the Efficiency of Cloud computing for E-learning Systems. WSEAS Transactions on Computers, Vol. 9, No. 1. 2010.

31. Raghupathi. W and Raghupathi. V. Big data analytics in healthcare: promise and potential. Health information science and systems, Vol. 2, No.3. 2014.

32. Sahar M. K. Big-data Management using Map Reduce on Cloud: A case study. EEG Images' Data, Al-Khwarizmi Engineering Journal, Vol. 13, No.1. 2017.

33. Shimaa O., Mona N. Cloud Computing: The Future of Big Data Management. International Journal of Cloud Applications and Computing, Vol. 5, No. 2. 2015.

34. Subashini, S., and Kavitha, V. A survey on security issues in service delivery models of cloud computing. Journal of Network and Computer Applications, Vol .34, No.1. 2011.

35. Vadivel. M., and Raghunath.V. Enhancing Map-Reduce Framework for Bigdata with Hierarchical Clustering. International Journal of Innovative Research in Computer and Communication Engineering, Vol. 2, No. 1. 2014.

36. Vashist, S., and Gupta, A. A Review on Distributed File System and Its Applications. International Journal of Advanced Research in Computer Science, Vol.5, No. 7. 2014.

37. Yusuf Perwej. An Experiential Study of the Big Data. International Transaction of Electrical and Computer Engineers System, Vol. 4, No. 1, 2017. 